\title{
EVALUATION OF CYTOTOXICITY OF THE AQUEOUS LEAF EXTRACT OF Pogostemon heyneanus BENTH. (JAVA PATCHOULI)
}

\author{
ANJANA SHEELA* and JOHN ERNEST THOPPIL \\ Cell and Molecular Biology Division, Department of Botany, University of Calicut, \\ Malappuram 673635, Kerala, India
}

Received 4 July 2015/Accepted 27 January 2017

\begin{abstract}
Several plants have been recently reported to possess anticancer potential. Allium cepa root tip assay is a preliminary study to assess the cytotoxic effect of plant extracts. The cytotoxic activity of plants can be correlated to their anticancer potential. Cytotoxic potential of Pogostemon heyneanus (Lamiaceae) was evaluated using $A$. cepa root meristematic cells. This study was aimed at analyzing cytotoxic potential of $P$. heyneanus using Allium cepa root tip assay. Four different concentrations of the aqueous leaf extracts at three different durations were examined. Distilled water was used as control. The extract was found to be cytotoxic at all tested concentrations, when compared to control. Mitotic index was found to be decreasing with the increase in extract concentrations and treatment durations. The aqueous extract of $P$. heyneanus was found to be an effective cytotoxic agent, inducing various clastogenic and nonclastogenic aberrations such as chromosome gaps, bridges, multipolar anaphase, fragments, nuclear budding and lesions, hyperchromasia, laggards and mitotic pairing.
\end{abstract}

Keywords: Allium cepa assay, anti-mitotic, chromosomal aberrations, cytotoxicity, Pogostemon heyneanus

\section{INTRODUCTION}

Recent years have witnessed the importance of plant-derived herbal medicines against many dreadful diseases. The cytotoxic potential of plant extracts can be tested preliminarily for their anticancer activity using Allium cepa assay. $P$. heyneanus, commonly called as Java Patchouli, is an aromatic species of Lamiaceae family. The plant is used to make the pungent, dark amber colored Patchouli oil, containing patchoulene, patchouli alcohol and eugenol as the major components. The oil possesses antibacterial activity against Escherichia coli, Staphylococcus aureus, Streptococcus pyogenes, Bacterium coli, Bacterium typhosum and Mycobacterium tuberculosis. It is also used in insect-repellent preparations. Essential oil extracted from the leaf was reported to possess remarkable larvicidal potential against Aedes albopictus (Anjana \& Thoppil 2013). Another species of the genus, P. cablin, has been reported to be having anticancer properties (Jeong et al. 2013).

\footnotetext{
* Corresponding author: anjana.s586@gmail.com
}

A wide variety of secondary metabolites obtained from medicinal plants possesses the ability to treat cancer. They exhibit cytotoxic effect by interfering with cell-cycle kinetics (GaliMuhtasib \& Bakkar 2002). These medications are effective against proliferating cells. These medications produce cytotoxic effect either by damaging the cell DNA during the S-phase of the cell cycle or by blocking the formation of mitotic spindle (Sehgal et al. 2006). Plant cytotoxic bioassays have a good correlation with mammalian test systems, validating the application of plant-based medications for genotoxic assays (Jovtchev et al. 2002; Yi \& Meng 2003; Çelik \& Äslanturk 2006, 2007). Toxicological tests using Allium cepa was found to have high correlation with other test systems (MIT-217 cell test with mice, rats or humans in vivo) and could be used in toxicological research (Lubini et al.2008).

There are no previous reports on the cytotoxic activities of $P$. heyneanus and therefore, the present study was aimed at evaluating the cytotoxic and antimitotic properties of $P$. heyneanus. 


\section{MATERIALS AND METHODS}

\section{Collection of Plant Materials}

Plant materials of $P$. heyneanus was obtained from the Centre of Medicinal Plants Research, Arya Vaidya Sala, Kottakkal, Kerala, India. The collected plant materials were maintained in the greenhouse and authenticated by Dr A.K. Pradeep, Assistant Professor, Department of Botany, University of Calicut, Kerala India. A voucher specimen was deposited at the Calicut University Herbarium (CALI 123733).

\section{Preparation of Leaf Extracts}

Fresh leaves of $P$. heyneanus were collected from the plants grown in the greenhouse and were rinsed thoroughly, shade dried and then ground into powder. The crude extract was prepared by boiling the dried powdered material in distilled water for 30 minutes. The extracts were prepared in four different concentrations $(0.5,0.1,0.05$ and $0.01 \%)$. The extracts were then filtered to remove particulate matter.

\section{Allium cepa Root Tip Assay}

Fresh and healthy bulbs of Allium cepa were obtained from the local market. The bulbs were germinated over water before being transferred to the test plant extracts. When the roots were about $5 \mathrm{~mm}$ long, the bulbs were placed on beakers containing $P$. beyneanus leaf extracts of four different concentrations $(0.5,0.1,0.05$ and $0.01 \%$ ), such that the roots were immersed in the extracts. The roots were immersed for 3 different durations, i.e. 2, 1 and $1 / 2$ hours. The sprouted roots were also treated with distilled water, which served as control. The experimental set up had five replicates.

The root tips were fixed in Carnoy's fluid (1 part of glacial acetic acid: 2 parts of absolute alcohol) after the treatment. These roots were then hydrolyzed in $1 \mathrm{~N} \mathrm{HCl}$ for 5 minutes. After hydrolysis, the roots were washed in distilled water. Root tips were cut into 1 - $2 \mathrm{~mm}$ long pieces and placed on a glass slide. A small drop of $2 \%$ aceto-orcein was placed on the root tip and the root tip was squashed. The slides were then scanned under Leica DM 1000 trinocular research microscope and photomicrographs were taken.
The numbers of cells, dividing and nondividing, were recorded. The degree of chromosomal aberration was expressed as the percentage of aberrant cells, which was calculated as the number of aberrant cells to the total number of cells examined. Mitotic Index (MI) was calculated by expressing the numbers of dividing cells as a percentage of total cells counted for each treatment and the control.

$$
\begin{aligned}
& \text { Percentage aberration }=\frac{\text { Numbers of aberrant cells }}{\text { Total number of cells }} \times 100 \\
& \text { Mitotic Index }=\frac{\text { Numbers of dividing cells }}{\text { Total number of cells }} \times 100
\end{aligned}
$$

\section{Statistical Analysis}

The data were analyzed using one way analysis of variance (One-way ANOVA). Means of the mitotic indices and chromosome aberrations with standard errors for each concentration of the extracts were calculated. Duncan's multiple range test was performed to determine the significant differences between the different treatments made. Statistical significance was accepted for $p<0.05$ (Auti et al. 2010). All statistical analyses were carried out using SPSS 17.0 statistical package.

\section{RESULTS AND DISCUSSION}

Mitosis was normal in the root tips kept as control, whereas the mitotic indices of all $A$. cepa roots treated with $P$. heyneanus leaf extracts were significantly lower than the mitotic index of control (Table 1).

The mitotic index rates were found to be decreasing with the increasing concentrations of the aqueous extract compared with the control (Table 1). Chromosome aberrations were observed in all stages of mitosis. Major clastogenic abnormalities observed were nuclear budding and lesions, chromosome fragments and gaps, ring chromosomes, chromosome bridges, stickiness, hyperchromasia and non-clastogenic aberrations including stellate anaphase, ball telophase, equatorial separation of chromosomes, chromosome laggards, misorientation at metaphase, hyperploids and hypoploid cells, double metaphase, early ball metaphase, mitotic pairing at metaphase, 
Table 1 Percentage of mitotic indices and chromosomal aberrations observed in Allium cepa root meristems treated with P. heyneanus leaf extracts

\begin{tabular}{|c|c|c|c|c|c|c|}
\hline \multirow{2}{*}{ Concentration } & \multicolumn{3}{|c|}{ Mitotic index $( \pm \mathrm{SE})$} & \multicolumn{3}{|c|}{$\%$ of aberrant cells $( \pm$ SE) } \\
\hline & $1 / 2$ hour & 1 hour & 2 hours & $1 / 2$ hour & 1 hour & 2 hours \\
\hline Control & $26.00 \pm 0.86^{\mathrm{a}}$ & $23.14 \pm 0.94^{a}$ & $25.47 \pm 0.09 \mathrm{a}$ & $0^{\mathrm{a}}$ & $0^{a}$ & $0^{\mathrm{a}}$ \\
\hline $0.01 \%$ & $17.11 \pm 3.00^{\mathrm{b}}$ & $16.37 \pm 1.50^{\mathrm{b}}$ & $16.23 \pm 1.39^{\mathrm{b}}$ & $36.03 \pm 0.75^{\mathrm{b}}$ & $41.81 \pm 0.56^{\mathrm{b}}$ & $46.07 \pm 1.30^{\mathrm{b}}$ \\
\hline $0.05 \%$ & $15.67 \pm 0.34^{b}$ & $15.10 \pm 0.93^{\mathrm{b}}$ & $15.09 \pm 0.80^{\mathrm{b}}$ & $39.16 \pm 1.32^{\mathrm{bc}}$ & $43.64 \pm 1.82^{\mathrm{bc}}$ & $48.14 \pm 0.93^{\mathrm{bc}}$ \\
\hline $0.1 \%$ & $14.32 \pm 1.31^{b}$ & $14.30 \pm 1.31^{b}$ & $13.83 \pm 0.50 b^{c}$ & $39.50 \pm 1.86^{\mathrm{bc}}$ & $47.98 \pm 3.07 \mathrm{c}$ & $51.60 \pm 2.61^{c}$ \\
\hline $0.5 \%$ & $13.39 \pm 0.62^{b}$ & $12.89 \pm 1.12^{\mathrm{b}}$ & $12.14 \pm 0.52^{c}$ & $42.88 \pm 2.88^{c}$ & $48.32 \pm 1.61^{c}$ & $62.85 \pm 1.91^{\mathrm{d}}$ \\
\hline
\end{tabular}

Note: Numbers followed by the same letters in the same column are not significantly different at $p<0.05$

multipolar anaphase, pole to pole arrangement at metaphase and vagrant chromosomes at metaphase (Fig. 1).

There were significant differences $(p<0.05)$ between treated groups and control group in mitotic index. Low mitotic index observed in the treated root tips might be due to direct genotoxic effect of $P$. heyneanus extract. The percentage of mitotic indices and chromosomal aberrations induced by different concentrations of the extract at different treatment durations are summarized in Table 1.

Decrease in mitotic index rates explained cytotoxicity of the aqueous extract. This might be due to the obstruction of the onset of prophase, the arrest of one or more mitotic phases, or the slowing of the rate of cell progression through mitosis (Fiskesjo \& Levan 1993). Reduction in the mitotic activity could also be due to inhibition of DNA synthesis or a blocking in the G2 phase of the cell cycle, preventing the cell from entering mitosis (Christopher \& Kapoor 1988).

Chromosomal aberrations are changes in chromosome structure resulting from a break or exchange of chromosomal material. Most of chromosomal aberrations observed in cells are lethal, but there are many corresponding aberrations that are viable and can cause genetic effects, either somatic or inherited (Sudhakar et al. 2001; Akinboro \& Bakare 2007).

Aberrations observed at the interphase stage included nuclear lesions (Fig. 1F) and nuclear budding (Fig. 1P). The presence of nuclear lesions offers cytological evidence for the inhibitory action on DNA biosynthesis (Majewska et al. 2003). Nuclear buds were observed to originate from the nuclear envelope in situ at certain regions of the interphase nucleus of the treated cells and these might be a result of the excessive production of nucleic acids and proteins, induced by cytotoxicants (Akaneme \& Iyioke 2008).

Stickiness (Fig. 1T) might result from improper folding of chromosome fibers which made the chromatids connected by means of subchromatid bridges (Hellgren \& Morre 1992). Chromosome gaps (Fig. 1D), which were distributed at random on the chromosomes, were formed by the action of mutagenic substances (McGill et al. 1974). Chromosome bridges (Fig. 1B \& 1T) and fragments (Fig. 1C) were clastogenic effects, resulting from chromosome and chromatid breaks (Fiskesjo 1997). Ring chromosomes (Fig. 1R) might arise due to the spontaneous breakage of chromosomal ends, followed by the joining of the raw ends of the chromosomes (Singh 2003). Ball metaphase (Fig. 1G) might be due to the localized activity of spindle apparatus at the centre, so that the centromeres remained at the equator and arms radiated in different directions, in the form of a ball. In ball telophase (Fig. 1A), the sister chromatids separated into a hollow ball of chromosomes that resulted from the early cleavage divisions in some aberrant cells (Morgan 2006).

Separation of daughter chromosomes parallel to the equator rather than towards the poles (Fig. $1 \mathrm{H})$ was an acute aberrant condition that arose as 


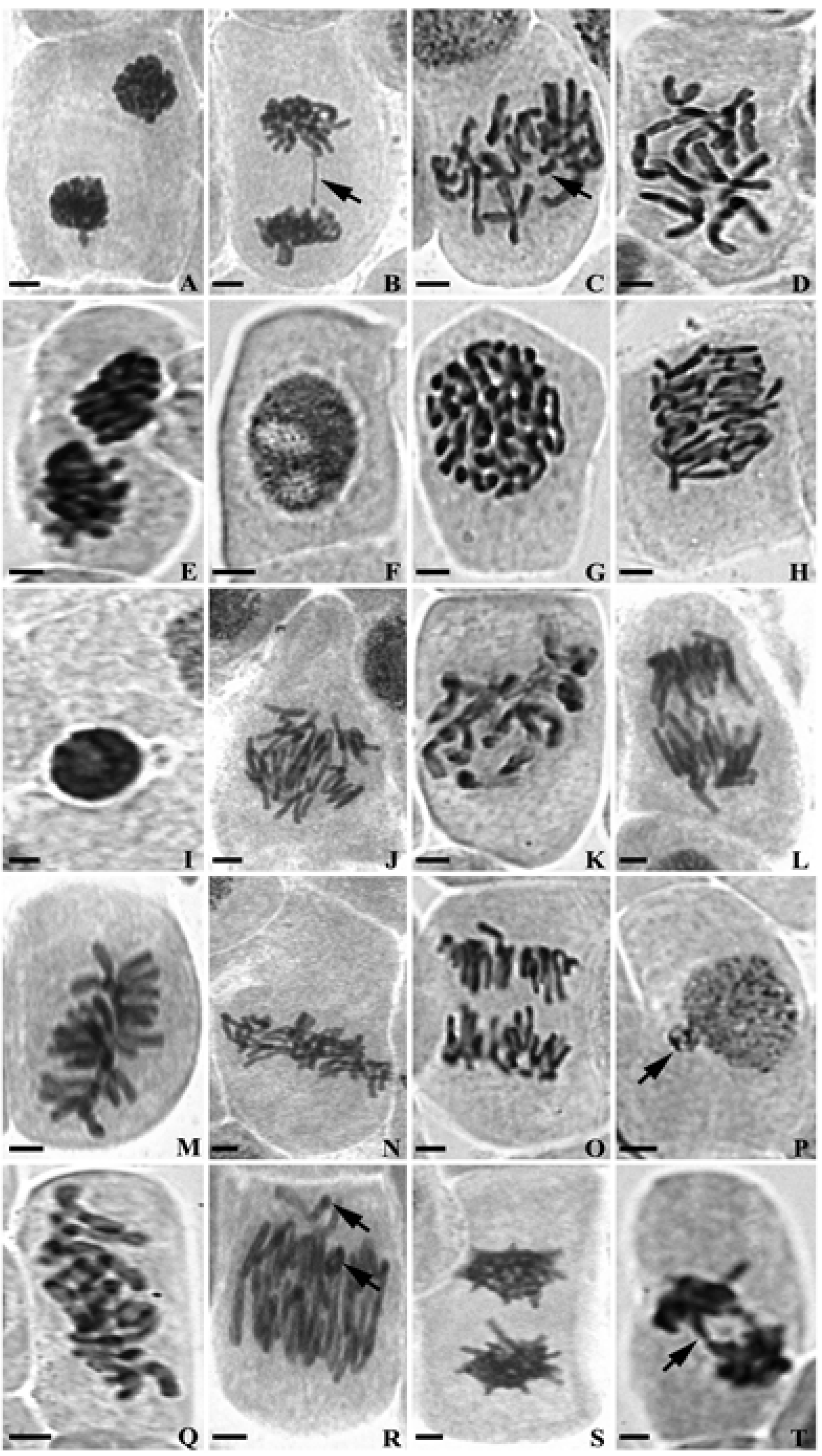

Figure 1 Chromosomal aberrations induced by different concentrations of aqueous leaf extracts of $P$. heyneanus

Notes: A) Ball telophase; (B) Chromosome bridge at anaphase; (C) Chromosome fragment at metaphase; (D) Chromosome gaps at metaphase; (E) Double metaphase; (F) Double nuclear lesion; (G) Early ball metaphase; (H) Equatorial separation at anaphase; (I) Hyperchromasia; (J) Hyperploid cell; (K) Hypoploid cell; (L) Laggards at anaphase; (M) Misorientation at metaphase; (N) Mitotic pairing at metaphase; (O) Multipolar anaphase; (P) Nuclear budding at interphase; (Q) Pole to pole arrangement at metaphase; (R) Ring and vagrant chromosomes at metaphase; (S) Stellate anaphase; (T) Sticky double chromosome bridge at anaphase 
a result of errors in the mitotic spindle assembly and dynamics (Ford \& Correll 1992). Stellate arrangement (Fig. 1S) of chromosomes might be due to the clumping of daughter chromosome groups in a star like manner and might be occurring as a result of the complete disturbance of spindle (Raj \& Rao 1972).

Hyperchromasia (Fig. 1I) was an extremely condensed and deeply staining state of interphase nucleus induced by toxic environmental chemicals or incompatible conditions, which might be caused by progressive heterochromatinization (Gernand et al. 2005). Misorientation of chromosomes (Fig. 1M) could be due to a distortion of the spindle apparatus or a tilt in the equatorial organization of metaphase chromosomes (Selim et al. 1981). The occurrence of hyperploid (Fig. 1J) cells might be attributed to spindle inhibition, lack of anaphase movement or failure of cell plate formation (Meske \& Hartmann 1995).

Abnormal pole to pole orientation of chromosomes (Fig. 1Q) at metaphase leading to equatorial separation of chromosomes at anaphase was an acute aberrant condition that arose as a result of irregular pathways of spindle assembly and abnormal spindle activity (Waters \& Salmon 1997). Multipolar anaphases (Fig. 1O) were consequences of weak $\mathrm{C}$-mitosis and could lead to aneuploidy (Fiskesjo 1988). The induction of vagrant chromosomes (Fig. 1R) led to the separation of unequal number of chromosomes in the daughter nuclei and subsequently formation of daughter cells with unequal sized or irregularly shaped nuclei at interphase (El-Ghamery et al. 2003). Laggards were whole chromosomes that failed to migrate to either pole at anaphase because of possible damage to the kinetochore (Asita \& Mokhobo 2013). Presence of hypoploid cells (Fig. 1K) might be due to the occurrence of multipolar mitosis or lagging chromosomes (Seoana et al. 2000). Mitotic pairing (Fig. 1N) was a rare abnormality which might be due to an increase in RNA content (Wen et al. 1989).

Mitotic Index (MI) measured the proportion of cells in the M-phase of the cell cycle. The inhibition of M-phase could be considered as cellular death or a delay in the cell proliferation kinetics (Nagpal \& Grover 1994; Ribeiro et al. 2016).
The decrease in mitotic index and the presence of these chromosomal aberrations in $A$. cepa root tips treated with $P$. heyneanus extract when compared with the control might be attributed to the presence of phytochemical constituents in the crude extract of $P$. heyneanus. $P$. heyneanus is rich in volatile oils containing compounds like patchouli alcohol, nerolidol, $\beta$-pinene etc. (Murugan et al. 2010). Patchouli alcohol, isolated from $P$. cablin was found to exhibit antitumor effect against human lung cancer cell lines (Lu et al.2016).

\section{CONCLUSIONS}

The aqueous extract of $P$. heyneanus possesses a dose dependent inhibitory effect on cell division of Allium cepa. Further studies are required to characterize and isolate the cytotoxic agents present in P. heyneanus.

\section{ACKNOWLEDGEMENTS}

The first author is thankful to the Council for Scientific and Industrial Research (CSIR), India for funding this study.

\section{REFERENCES}

Akaneme FI, Iyioke IV. 2008. Mutagenic potentials of the sterilizing fluid - Purital on root tip mitosis of Allium cеpa. Bio Res 6:293-7.

Akinboro A, Bakare AA. 2007. Cytotoxic and genotoxic effects of aqueous extracts of five medicinal plants on Allium cepa Linn. J Ethnopharmacol 112:470 -5.

Anjana S, Thoppil JE. 2013. Chemical composition of the essential oils of four Pogostemon spp. and their larvicidal activity against Aedes albopictus Skuse (Diptera: Culicidae). Int J Environ Biol 3:26-31.

Asita AO, Mokhobo MM. 2013. Clastogenic and cytotoxic effects of four pesticides used to control insect pests of stored products on root meristems of Allium cepa. Environ Nat Resour Res 3:133-45.

Auti S, Pagare R, Ahire D, Sawale V. 2010. Cytogenetical studies on the effect of omnacortil on root tip cells of Allium cepa L. J Cell Tissue Res 10:2331-5.

Çelik TA, Äslanturk ÖS. 2006. Anti-mitotic and antigenotoxic effects of Plantago lanceolata aqueous extract on Allium cepa root tip meristem cells. Biologia 61:693-7. 
Çelik TA, Äslanturk ÖS. 2007. Cytotoxic and genotoxic effects of Lavandula stoechas aqueous extracts. Biologia 62:292-6.

Christopher HB, Kapoor MB. 1988. The cytogenetic effects of sodium salicylate on the root meristem cells of Allium sativa L. Cytologia 54:203-9.

El-Ghamery AA, El-Kholy MA, Abou El-Yousser MA. 2003. Evaluation of cytological effects of $\mathrm{Zn}^{2+}$ in relation to germination and root growth of Nigella sativa L. and Triticum aestivum L. Mutat Res. 537:29-41.

Fiskesjo G. 1988. The Allium test-an alternative in environmental studies: the relative toxicity of metal ions. Mutat Res 197:243-60.

Fiskesjo G. 1997. Allium test for screening chemicals evaluation of cytological parameters. In: Wang W, Gorsuch JW, Huges JS, editors. Plants for Environmental Studies. New York (US): CRC Lewis Publishers. p. 307-33.

Fiskesjo G, Levan A. 1993. Evaluation of the first ten MEIC chemicals in the Allium test. ATLA 21:139-49.

Ford JH, Correll AT. 1992. Chromosome errors at mitotic anaphase. Genome 35:702-5.

Gali-Muhtasib H, Bakkar N. 2002. Modulating cell cycle: current applications and prospects for future drug development. Current Cancer Drug Targets. 2:3096.

Gernand D, Rutten T, Varshney A, Rubtsova M, Prodanovic S, Bruss C, Kumlehn J, Matzk F, Houben A. 2005. Uniparental chromosome elimination at mitosis and interphase in wheat and pearl millet crosses involves micronucleus formation, progressive heterochromatinisation and DNA fragmentation. Plant Cell 17:2431-8.

Hellgren L, Morre DJ. 1992. ATP-induced budding of nuclear envelope in vitro. Protoplasma 167:238-42.

Jeong JB, Choi J, Lou Z, Jiang X, Lee SH. 2013. Patchouli alcohol, an essential oil of Pogostemon cablin, exhibits anti-tumorigenic activity in human colorectal cancer cells. Int Immunopharmacol 16:184-90.

Jovtchev G, Stergios M, Schubert I. 2002. A comparison of $\mathrm{N}$-methyl-N-nitrosourea-induced chromatid aberrations and micronuclei in barley meristems using FISH techniques. Mutat Res 517:47-51.

Lu X, Yang L, Lu C, Xu Z, Qiu H, Wu J, Wang J, Tong J, Zhu Y, Shen J. 2016. Molecular role of EGFR-MAPK pathway in Patchouli Alcoholinduced apoptosis and cell cycle arrest on A549 cells in vitro and in vivo. Biomed Res Int Article ID4567580. $12 \mathrm{p}$.

Lubini G, Fachinetto JM, Laughinghouse HD, Paranhos JT, Silva ACF, Tedesco SB. 2008. Extracts affecting mitotic division in root-tip meristematic cells. Biologia 63:647-51.
Majewska AE, Wolska E, Sliwinska M, Furmanowa N, Urbanska A, Pietrosiuk A, Zobel A, Kuras M. 2003. Antimitotic effect, G2/M accumulation, chromosomal and ultrastructure changes in meristematic cells of Allium cepa L. root tips treated with the extract from Rhadiola rosea roots. Caryologia 56:337-51.

McGill M, Pathak S, Hsu TC. 1974. Effects of ethidium bromide on mitosis and chromosomes: A possible material basis for chromosome stickiness. Chromosoma 47:157-67.

Meske V, Hartmann E. 1995. Reorganisation of microfilaments in protonemal tip cells of the moss Ceratodon purpureus during the phototropic response. Protoplasma 188:59-69.

Morgan DO. 2006. The cell cycle: principles of control. London (UK): New Science Press Ltd. 169 p.

Murugan R, Mallavarapu GR, Padmashree KV, Rao RR, Livingstone C. 2010. Volatile oil composition of Pogostemon heyneanus and comparison of its composition with patchouli oil. Nat Prod Commun 5:1961-4.

Nagpal A, Grover IS. 1994. Genotoxic evaluation of systemic pesticides in Allium cepa. Nucleus 37:99105.

Raj A, Rao R. 1972. Cytological studies in Vicia faba L. treated with lathyrogens. Cytologia 37:245-56.

Ribeiro TP, Sousa TR, Arruda AS, Peixoto N, GoncalvesPJ, Almeida LM . 2016. Evaluation of cytotoxicity and genotoxicity of Hancornia speciosa latex in Allium cepa root model. Braz. J. Biol. 76:245-9.

Sehgal R, Roy S, Kumar VL. 2006. Evaluation of cytotoxic potential of latex of Calotropis procera and podophyllotoxin in Allium cepa root model. Biocell 30:9-13.

Selim AR, Hussein MM, Allam HZ, Farah AR. 1981. The effect of three synthetic organic insecticides (Nuvacron, Cyolan and Kelthane/Dimethoate) on the cytological features and morphological characters in cotton Gossypium barbadense L. Bull Fac Agric Cairo Univ 11:52-66.

Seoana AI, Giierci AM, Dulout FN. 2000. Mechanisms involved in the induction of aneuploidy: the significance of chromosome loss. Genet Mol Biol 23:4.

Singh RJ. 2003. Plant cytogenetics. Boca Raton (US): CRC Press. 133 p.

Sudhakar R, Gowda KNN, Venu G. 2001. Mitotic abnormalities induced by silk dyeing industry effluents in the cells of Allium cepa. Cytologia 66:235-9.

Waters JC, Salmon ED. 1997. Pathways of spindle assembly. Curr Opin Cell Biol 9:37-43. 
BIOTROPIA Vol. 24 No. 1, 2017

Wen F, Barnett FL, Liang GH. 1989. Somatic pairing and separation of chromosomes in root- tip cells of regenerated Sorghum plants. J Hered 80:159-60.
Yi H, Meng Z. 2003. Genotoxicity of hydrated sulfur dioxide on root tips of Allium sativum and Vicia faba. Mutat Res 537:109-14. 